\title{
REVIEWS
}

\section{Pulmonary arteriovenous malformations: a clinical review}

\author{
Mobeen Iqbal, Leonard J Rossoff, Harry N Steinberg, Kamel A Marzouk, David N Siegel
}

\begin{abstract}
Pulmonary arteriovenous malformations (PAVMs) are a rare clinical entity. Most of them are associated with hereditary haemorrhagic telangiectasia. The usual clinical presentation is exertional dyspnoea and hypoxaemia. The initial test of choice for screening is the $100 \%$ oxygen method. A pulmonary angiogram is needed to define the anatomy and guide transcatheter embolisation (TCE). TCE has been shown to be effective and safe with a very low recanalisation rate and has largely replaced surgery for PAVMs. Computed tomography of the chest can be used for the follow up of asymptomatic PAVMs and TCE.

(Postgrad Med f 2000;76:390-394)
\end{abstract}

Keywords: arteriovenous malformation; hypoxaemia; shunt study; embolisation

Pulmonary arteriovenous malformations (PAVMs) are abnormal direct communications between the pulmonary artery and vein. Most PAVMs are congenital but acquired causes of PAVMs include post-thoracic surgery, trauma, tuberculosis, actinomycosis, and schistosomiasis. ${ }^{1}$ PAVMs results in a right to left shunt, which if significant can cause symptoms. PAVMs can impair the normal filtering function of lungs and be a source of paradoxical embolism and systemic infections. ${ }^{2}$ Surgery was the only curative treatment available before the introduction of transcatheter embolisation (TCE), which is now generally accepted as the procedure of choice.

\section{Association with hereditary}

haemorrhagic telangiectasia

Most of congenital PAVMs (60\% to $90 \%)^{2}$ are associated with hereditary haemorrhagic telangiectasia an autosomal dominant disorder with mutations localised to chromosome locus $9 \mathrm{q} 3 .^{3}$ This gene encodes endoglin, which is the transforming growth factor- $\beta$ binding protein. ${ }^{4}$ Other mutations have been identified for activin receptor-like kinase 1 gene on chromosome locus $12 \mathrm{q}$, which controls blood vessel development and repair. Genetic heterogeneity in hereditary haemorrhagic telangiectasia has been shown in families that show linkage to other regions on the long arm of chromosome $12 .^{5}$
Box 1: Complications of PAVMs

Neurological

- Cerebral abscess

- Cerebrovascular accidents

- Migraine

- Seizures

Cardiovascular

- Pulmonary hypertension

- High output cardiac failure

- Paradoxical embolism

Pulmonary

- Haemoptysis

- Haemothorax

Haematological

- Polycythaemia

\section{Clinical features}

Symptoms related to PAVMs often develop between the fourth and sixth decades. The classical triad of hereditary haemorrhagic telangiectasia consists of epistaxis, telangiectasias, and a family history of the disorder. Common clinical features are epistaxis, dyspnoea haemoptysis, telangiectasias, cyanosis, clubbing (in the presence of right to left shunt), and gastrointestinal bleeding. ${ }^{67}$ Sometimes a bruit is audible on chest auscultation. As most of PAVMs are located at the bases of the lung, orthostatic hypoxaemia (orthodeoxia) can also occur. Platypnoea (improvement in dyspnoea on reclining) is associated with decreased blood flow through PAVMs in the supine position. ${ }^{8}$

\section{Complications}

PAVMs may result in serious complications, which can frequently be prevented with appropriate treatment. Neurological complications are the most commonly seen. These include strokes $(18 \%)$, transient ischaemic attacks (37\%), cerebral abscess (9\%), migraine (43\%), and seizures (8\%). ${ }^{9}$ Paradoxical embolism is the most common cause of non-infectious cerebrovascular accidents. Polycythaemia and coexistent cerebral arteriovenous malformations are rare causes of cerebrovascular accidents. ${ }^{9}$ Less common, but potentially life threatening complications, include haemothorax and haemoptysis. ${ }^{10}$

Box 1 lists the complications.
Submitted 23 July 1999 Accepted 27 October 1999 


\section{Diagnosis}

Depending on the clinical presentation the diagnosis of PAVMs is established by evidence of right to left shunt and imaging studies.

The $100 \%$ oxygen method, contrast echocardiography, and radionuclide imaging are nearly $100 \%$ sensitive for the detection of clinically significant PAVMs. The specificity of contrast echocardiography and radionuclide imaging is higher than the $100 \%$ oxygen method. ${ }^{9}$

$100 \%$ OXYGEN METHOD

The ease of performance and low cost make the $100 \%$ oxygen method a preferred initial study. The patient breathes $100 \%$ oxygen for 20 minutes. In normal persons partial pressure of oxygen $\left(\mathrm{pO}_{2}\right)$ rises to $80 \mathrm{kPa}$. Shunt fraction can be calculated by measuring $\mathrm{pO}_{2}$ and then using a shunt equation. If the shunt fraction is more than 5\% further studies are indicated. A formula for shunt fraction is shown below:

Shunt fraction $=\left(\mathrm{CcO}_{2}-\mathrm{CaO}_{2}\right) /\left(\mathrm{CcO}_{2}-\mathrm{CvO}_{2}\right)^{11}$

$\mathrm{CcO}_{2}$ is end capillary oxygen content of blood, $\mathrm{CaO}_{2}$ is arterial oxygen content, and $\mathrm{CvO}_{2}$ is venous oxygen content. The above equation is the most accurate method of calculating shunt fraction but it requires measurement of the mixed venous saturation and thus right heart catheterisation. There are simplified versions of above equation including:

Shunt fraction $=$

$\left(\mathrm{PAO}_{2}-\mathrm{PaO}_{2}\right) /\left(\mathrm{PAO}_{2}-\mathrm{PaO}_{2}+1670\right)^{11}$

$\mathrm{PAO}_{2}$ is alveolar oxygen tension and $\mathrm{PaO}_{2}$ is arterial oxygen tension.

The $100 \%$ oxygen method is not an error free method. The technique (air leaks) and duration of oxygen breathing (nitrogen wash out) can affect the results; $100 \%$ oxygen itself can cause atelectasis and small shunt fraction (up to $11 \%$ ). ${ }^{12}$

\section{CONTRAST ECHOCARDIOGRAPHY}

Contrast echocardiography is perhaps the most sensitive method for detection of PAVMs. It is non-invasive and widely available. Agitated saline is injected (to create bubbles) in a peripheral vein and echocardiography is performed. In normal conditions bubbles will be trapped in the lungs but in the presence of PAVMs they will quickly appear in the left atrium after three to five cardiac cycles in the absence of intracardiac shunt (where bubbles appear in less than three cardiac cycles). ${ }^{13}$ Contrast echocardiography does not quantify shunt fraction. It may be too sensitive for clinically insignificant PAVMs and for follow up of TCEs.

RADIONUCLIDE IMAGING

Radionuclide imaging is also a sensitive method and can quantify the shunt fraction but it cannot differentiate between a cardiac or pulmonary source of shunt. ${ }^{14}$

ULTRAFAST CONTRAST ENHANCED COMPUTED TOMOGRAPHY

Ultrafast contrast enhanced computed tomography has been shown to be more sensitive than conventional pulmonary angiograms for PAVMs and better in defining their architecture. Three dimensional helical computed tomography has also shown to be very accurate in analysing the PAVMs especially if combined with concomitant cross sectional images. ${ }^{15}$ The main advantage of helical computed tomography is non-invasiveness and avoidance of contrast injection. The disadvantage is false positive results with vascular tumours.

MAGNETIC RESONANCE IMAGING

The data on magnetic resonance imaging of PAVMs is not extensive. Recently, phase contrast cine sequences have been shown to be the most accurate of magnetic resonance imaging techniques (conventional spin magnetic resonance and rotation gated magnetic resonance). ${ }^{16}$ The main limitation to magnetic resonance techniques is expense and availability.

PULMONARY ANGIOGRAPHY

Pulmonary angiography remains the gold standard especially when a therapeutic intervention is planned. ${ }^{15}$ Subtraction angiography has largely replaced the conventional angiogram for PAVMs. Angiography supplies detailed information on morphology, complexity, and size of PAVMs.

\section{Screening}

All patients with hereditary haemorrhagic telangiectasia should undergo routine screening with the non-invasive techniques preferably with the $100 \%$ oxygen method. Family members of patients with hereditary haemorrhagic telangiectasia should also be screened for PAVMs. ${ }^{17}$ Though radionuclide imaging and contrast echocardiography are very sensitive and more specific than the $100 \%$ oxygen method, the cost and availability are the main limiting factors. Moreover contrast echocardiography can be too sensitive by detecting clinically insignificant microvascular shunts and radionuclide imaging does not differentiate between a cardiac or pulmonary source of AVMs.

After embolisation of PAVMs follow up screening may be indicated at one month and again at one year. Generally treated PAVMs disappear or are reduced to a fibrous strand by the end of one year. Any evidence of persistence suggests recanalisation and is an indication for re-embolisation. Thereafter spiral computed tomography scan should be done after every three to five years for development of new or growth of small PAVMs. ${ }^{219}$ Antibiotic prophylaxis is recommended for any procedure that may induce bacteraemia. Pregnant females with PAVMs are at high risk for complications such as increase in size, right to left shunt, pulmonary haemorrhage, and strokes. This suggests a hormonal influence on PAVMs and is an indication for screening. ${ }^{18}$

\section{Treatment}

TCE has revolutionised the treatment of PAVMs by virtually eliminating the need for surgery. Stainless steel coils and detachable balloons are the commonly used devices for TCE. The size of coil is critical, as larger coils 
may be difficult to form a tight nest and if too small can result in paradoxical coil embolism. The introduction of new detachable steel coils has eased the problem of selecting the right size. Detachable coils can be withdrawn if they are not of right size or can be reinserted if not properly placed. Detachable balloons are preferred by some workers due to their ability to be retrieved if of the incorrect size but with the availability of detachable coils this is no longer an issue. ${ }^{12}$

The femoral vein is the preferred site for catheterisation. Both right and left sided pulmonary angiograms are performed using digital subtraction technique. The feeding artery of a PAVM is selectively catheterised and the steel coil is advanced through the catheter in the feeding artery close to the PAVM sac. The pulmonary angiogram is repeated to see the blood flow to the PAVM. Multiple coils may be required until the blood flow to the PAVM has stopped. If the balloon technique is employed, after selective catheterisation of the feeding artery a silicon or gold valve balloon is advanced over the catheter and inflated with contrast material. A pulmonary angiogram is performed to ensure PAVM occlusion and the balloon is detached. ${ }^{12} 9$

Efficacy and safety of TCE has been demonstrated in many studies. In a long term study, 45 patients with PAVMs more than $8 \mathrm{~mm}$ were treated successfully with embolotherapy and only $16 \%$ required repeated TCE for persistent PAVMs or recanalisation. ${ }^{19}$ Current indications for TCE include the prevention of complications in larger (feeding artery diameter $>3 \mathrm{~mm}$ ) and symptomatic PAVMs. Persistence of PAVMs at one year after TCE on computed tomography is evidence of recanalisation or inadequate embolisation and represents an indication for pulmonary angiography with repeat TCE. ${ }^{2}$

The most common complications of TCE are procedure related (contrast allergy, local haematoma at puncture site, etc) and pleurisy. Delayed pleurisy (four to six weeks after the procedure) with fever and infiltrates has been reported mainly with larger PAVMs. ${ }^{2}{ }^{19}$ Rarely, angina and migration of coils from PAVM sac to pulmonary vein can result in a paradoxical coil embolism. Recanalisation after embolisation is not common and has been attributed to elongation of or an insufficient number of coils. This can be avoided by placing coils or detachable balloons within or as near to a PAVM as possible. This prevents bronchial arterial communication with the pulmonary artery. ${ }^{20}$

MEDICAL THERAPY

Medical therapy in the form of hormones, danazol, octreotide, desmopressin, and aminocaproic acid have been tried with variable success only in epistaxis and gastrointestinal bleeding. There are no data of their use in PAVMs. ${ }^{21}$

LUNG TRANSPLANTATION

Lung transplantation can be considered for patients with diffuse multiple PAVMs unresponsive to TCE, however, relative survival data are

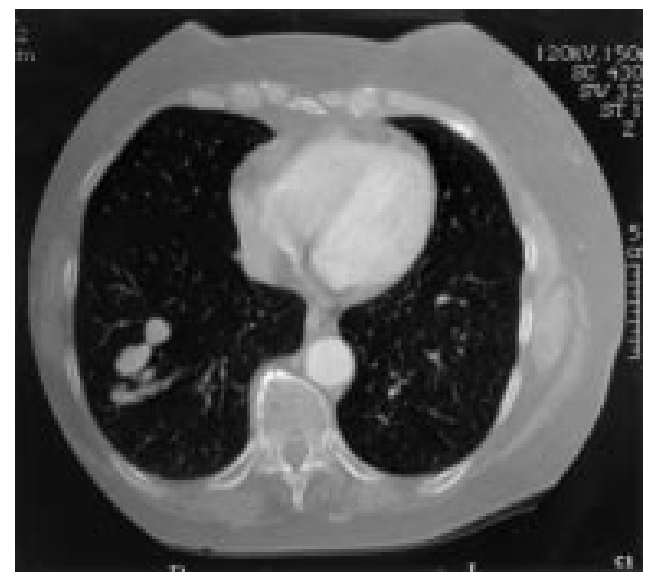

Figure 1 High resolution computed tomography showing a PAVM with a feeding artery and draining veins in the right lower lobe.

sparse. The timing of transplantation remains difficult. Our third patient with diffuse disease did not respond to multiple embolisations and demonstrated pulmonary hypertension with borderline oxygen saturation on room air. Such a patient likely represents a good candidate for early referral for lung transplantation.

In conclusion, PAVMs are most commonly associated with hereditary haemorrhagic telangiectasia. Family members of the index patient with hereditary haemorrhagic telangiectasia should be screened for the disease. The $100 \%$ oxygen method for shunt calculation remains the preferred initial screening method. TCE is the treatment of choice and can be repeated as needed. Ultrafast computed tomography is the imaging modality of choice for follow up after TCE and also for asymptomatic PAVMs $<3 \mathrm{~mm}$.

\section{Case reports}

CASE 1

A 66 year old white women was referred to our clinic for non-resolving pneumonia. She was treated with antibiotics for mild haemoptysis with mucopurulent sputum. Follow up chest radiography showed no improvement. Her exertional dyspnoea worsened and she developed new cognitive deficits. She had a transient ischaemic attack four years before. Her family history was unremarkable.

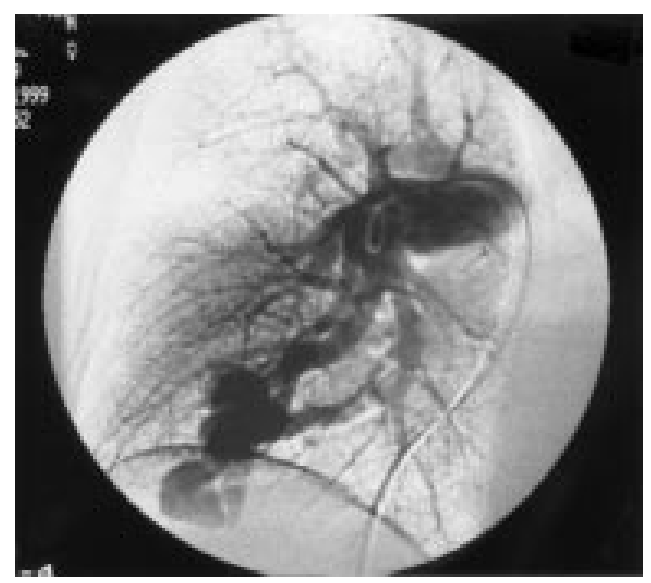

Figure 2 Pulmonary angiogram showing the anatomy and size of a PAVM. 


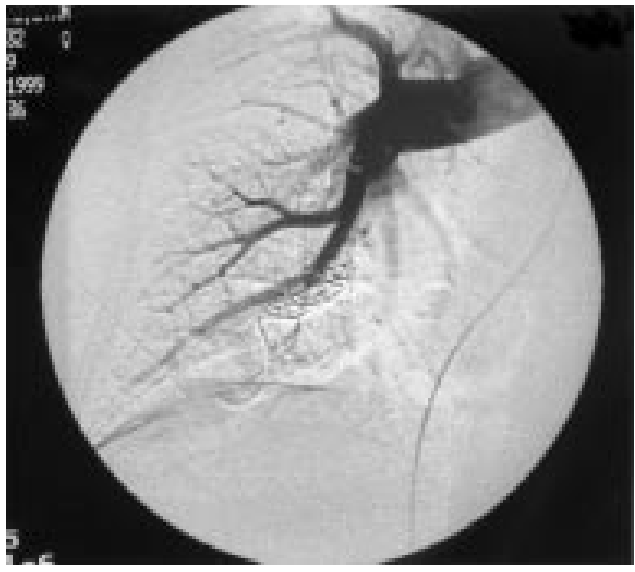

Figure 3 Pulmonary angiogram after embolisation and complete obliteration of a PAVM.

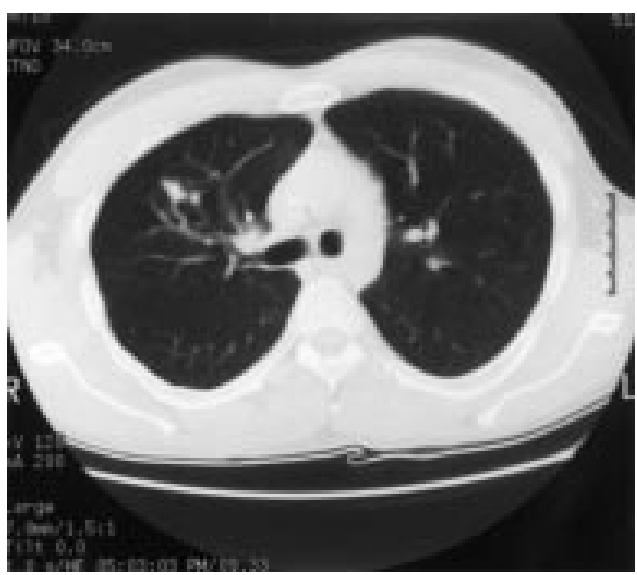

Figure 4 Computed tomography demonstrating a PAVM in the right upper lobe.

On physical examination all vital signs were normal. The significant findings were central cyanosis and a systolic murmur best heard at the apex and radiating to the axilla. Chest

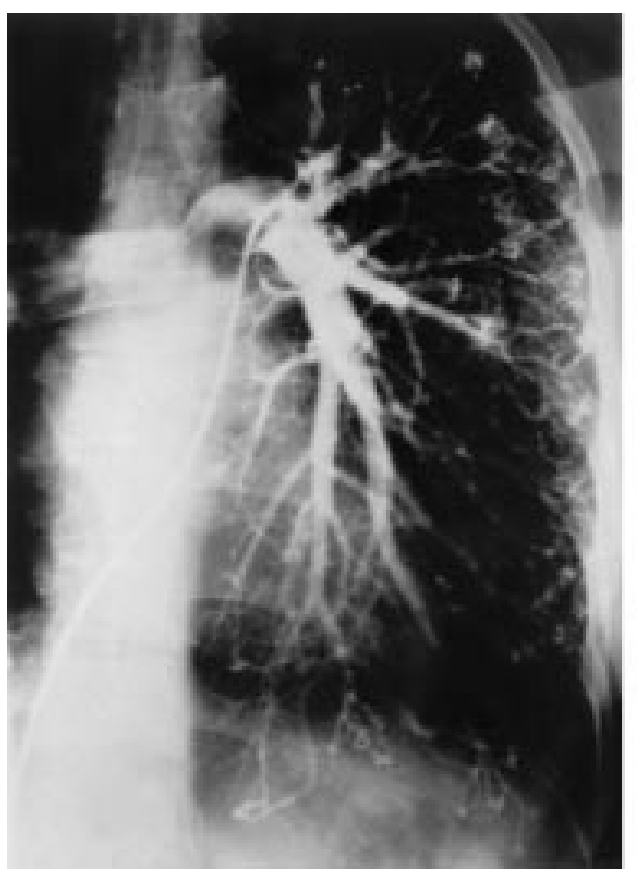

radiography revealed a right lower lobe lobulated mass. Computed tomography revealed a lobulated opacity with a feeding artery and two draining veins (fig 1). A diagnosis of PAVM was made on the clinical information. The calculated shunt fraction was $14 \%$. Pulmonary angiography was performed with successful TCE by metalic coils (figs 2 and 3 ). The shunt fraction immediately decreased to $6 \%$ after the procedure and the patient was discharged within 24 hours. Her clinical improvement persisted in subsequent follow up.

CASE 2

A 34 year old white man and lifelong nonsmoker with hereditary haemorrhagic telangiectasia was admitted for fever and headache. There was no history of cough, haemoptysis, or chest pain. He noted gradually worsening exertional dyspnoea for eight to nine months and complained of an episode od epistaxis a few months before. He had a history of right middle lobectomy 20 years before for symptomatic PAVM. The family history was unremarkable. Physical examination revealed scattered telangiectasias on the oral mucosa and scalp. Examination of the lungs was normal and no neurological deficits were detected. Magnetic resonance imaging of the brain revealed a right parietal lesion consistent with cerebral abscess. The abscess was aspirated stereotactically and treated with broad spectrum antibiotics. $\mathrm{He}$ improved clinically but was persistently hypoxaemic on room air. The calculated shunt fraction was $18 \%$. Computed tomography without contrast showed a $2.0 \times 2.5 \mathrm{~cm}$ PAVM in the right upper lobe (fig 4) and a $1 \mathrm{~cm}$ PAVM in the right lower lobe (not shown). Pulmonary angiography was performed with TCE using titanium coils with successful occlusion of both PAVMs. The subsequent shunt calculation was normal (less than $5 \%$ ).

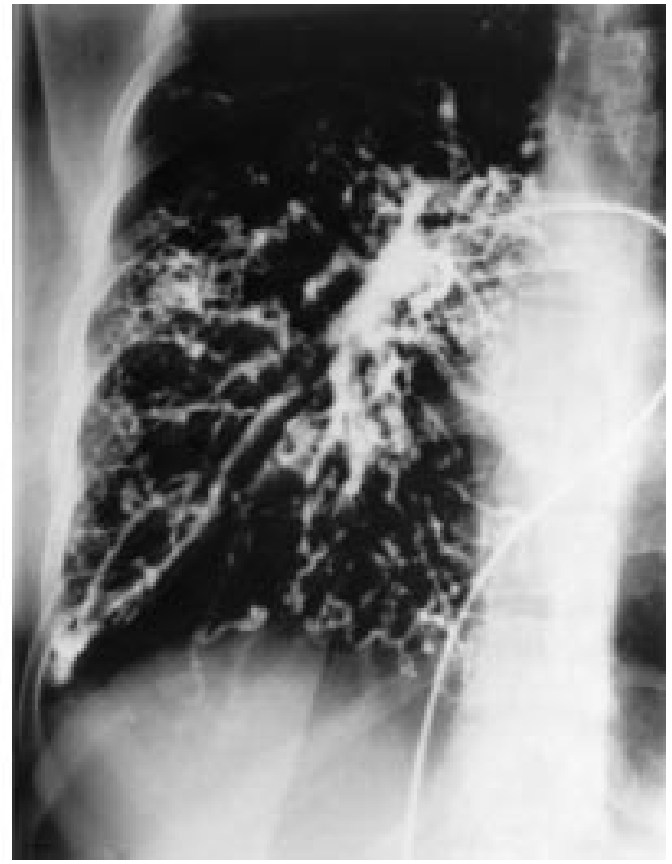

Figure 5 Pulmonary angiogram showing multiple bilateral PAVMs and evidence of previous embolisations. 


\section{Learning points}

- PAVMs are usually present with dyspnoea and unexplained hypoxaemia.

- PAVMs can cause neurological complications like cerebral abscess and cerebrovascular accidents.

- The $100 \%$ oxygen method to calculate shunt fraction is the initial screening method of choice.

- Pulmonary angiography is required to evaluate size, anatomy, and guide treatment for symptomatic PAVMs.

- TCE is the treament of choice and can be repeated safely.

- High resolution computed tomography can also screen for PAVMs, follow lesions $<3 \mathrm{~mm}$ in diameter, and monitor for recurrence after treatment.

- Patients with PAVM should receive antibiotic prophylaxis for procedures likely to induce bacteraemia.

- Family members of patients with PAVMs should be screened.

CASE 3

A 31 year old white women with a known diagnosis of Osler-Wber-Rendu disease ( hereditary haemorrhagic telangiectasia) presented with increasing dyspnoea on exertion. Her symptoms started at age 13 when she noted an inability to keep up with her peers in normal activities. In her late 20 s she had two transient ischaemic attacks with no residual deficit. Three previous pulmonary angiograms were performed with multiple TCEs with the last done six years before (fig 5, left and right). Her only current medication was an oral contraceptive for hereditary haemorrhagic telangiectasia. Her family history was significant for PAVMs in her father and grandmother. Physical examination revealed telangiectasias on her forehead and buccal surface of the oral mucosa. A bruit was heard in the distribution of the right lower lobe posteriorly. The calculated shunt fraction was $24 \%$. Echocardiography showed an enlarged hyperdynamic left ventricle with evi- dence of mild pulmonary hypertension. TCE was not attempted for fear of worsening the pulmonary hypertension.

1 Coley SC, Jackson JE. Pulmonary arteriovenous malformations. Clin Radiol 1998;53:396-404.

2 White RI Jr, Pollak JS, Wirth JA. Pulmonary arteriovenous malformations: diagnosis and transcatheter embolotherapy. F Vasc Interv Radiol 1996;7:787-804.

3 Shovlin CL, Hughes JM, Tuddenham EG, et al. A gene for hereditary hemorrhagic telangiectasia maps to chromosome 9q3. Nat Genet 1994;6:205-9.

4 McAllister KA, Grogg KM, Johnson DW, et al. Endoglin, a TGF-beta binding protein of endothelial cells, is the gene 1994;8:345-51.

5 Johnson DW, Berg JN, Baldwin MA, et al. Mutations in the activin receptor-like kinase 1 gene in hereditary haemorrhagic telangiectasia type 2. Nat Genet 1996;13:189-95.

6 Guttmacher AE, Marchuk DA, White RI. Hereditary hemorrhagic telangiectasia. N Engl f Med 1995;333:918-24.

7 Haitjema T, Westermann CJ, Overtoom TC, et al.

Hereditary hemorrhagic telangiectasis (Osler-Weber-Rendu disease): new insights in pathogenesis, complications, and disease): new insights in pathogenesis, comp
treatment. Arch Intern Med 1996;156:714-19.

8 Terry PB, White RI, Barth KH, et al. Pulmonary arteriovenous malformations: physiologic observations and results of therapeutic balloon embolization. $N$ Engl f Med 1983;308:1197-200.

9 Gossage JR, Kanj G. Pulmonary arteriovenous malformations. A state of the art review. Am Rev Respir Crit Care Med 1998;58:643-61.

10 Ference BA, Shannon TM, White RI Jr, et al. Life threatening pulmonary hemorrhage associated with pulmonary telangiectasia. Chest 1994;106:1387-90.

11 Chiang ST. Anomogram for veenous shunt (Qs/Qt) calculation. Thorax 1968;23:563-5.

12 Wagner PD, Laravuso RB, Uhl RR, et al. Continuous distributions of ventilation-perfusion ratios in normal subjects butions of ventilation-perfusion ratios in normal subject

13 Barzeli B, Waggoner AD, Spessert C, et al. Two dimensional contrast echocardiography in the detection and follow-up of congenital pulmonary arteriovenous malformations. Am f Cardiol 1991;68:1507-10

14 Whyte MKB, Peters AM, Hughes JMB, et al. Quantification of right to left shunt at rest and during exercise in patients with pulmonary arteriovenous malformation. Thorax 1992; 47:790-6.

15 Remy J, Remy-Jardin M, Giraud F, et al. Angioarchitecture of pulmonary arteriovenous malformations: clinical utility of three-dimensional helical CT. Radiology 1994;191:65764.

16 Silverman JM, Julien PJ, Herfkens RJ, et al. Magnetic resonance imaging evaluation of pulmonary vascular malformanance imaging evaluation of pur. Chest 1994;106:1333-8.

17 Haitjema T, Disch F, Overtoom TTC, et al. Screening family members of patients with hereditary hemorrhagic telangiectasia. Am $\mathfrak{f}$ Med 1995;99:519-24.

18 Shovlin CL, Winstock AR, Peters AM, et al. Medical complications of pregnancy in hereditary haemorrhagic telangiectasia. $Q \mathcal{F}$ Med 1995;88:879-87.

19 Lee DW, White RI Jr, Egglin TK, et al. Embolotherapy of large pulmonary arteriovenous malformations: long-term results. Ann Thorac Surg 1997;64:930-40.

20 Sagara K, Miyazono N, Inoue H, et al. Recanalization after coil embolotherapy of pulmonary arteriovenous malformations: study of long-term outcome and mechanism malformations: study of long-term outcome and mechanism

1 . Marshall JK, Hunt RH. Hormonal therapy for bleeding
gastrointestinal mucosal vascular abnormalities: a promising gastrointestinal mucosal vascular abnormalities: a prom
alternative. Eur $\mathcal{f}$ Gastroenterol Hepatol 1997;9:521-5. 